Article

\title{
Highly Conductive and Flexible Gel Polymer Electrolyte with Bis(Fluorosulfonyl)imide Lithium Salt via UV Curing for Li-Ion Batteries
}

\author{
Lei Jin ${ }^{1}{ }^{1}$, Faiz Ahmed ${ }^{1}$, Taewook Ryu ${ }^{1}$, Sujin Yoon ${ }^{1}$, Wei Zhang ${ }^{1}$, Yonghoon Lee ${ }^{1}$, \\ Daeho Kim ${ }^{1}$, Hohyoun Jang ${ }^{2}$ and Whangi Kim ${ }^{1, *}$ (I) \\ 1 Department of Applied Chemistry, Konkuk University, 268 Chungwon-daero, \\ Chungju-si 27478, Chungcheongbuk-do, Korea; jinlei8761@naver.com (L.J.); \\ faiz2310@gmail.com (F.A.); gundam0924@naver.com (T.R.); ysj920126@naver.com (S.Y.); \\ arno_zw@hotmail.com (W.Z.); jedo50@naver.com (Y.L.); wskdh2004@naver.com (D.K.) \\ 2 Department of Liberal arts, Konkuk University, 268 Chungwon-daero, \\ Chungju-si 27478, Chungcheongbuk-do, Korea; 200417450@kku.ac.kr \\ * Correspondence: wgkim@kku.ac.kr; Tel.: +82-43-840-3579; Fax: +82-43-851-4169
}

Received: 27 September 2019; Accepted: 28 October 2019; Published: 30 October 2019

\begin{abstract}
A series of new self-standing gel polymer electrolytes (SGPEs) were fabricated by ultraviolet (UV) curing and investigated for application in flexible lithium-ion batteries. Compared with traditional gel polymer electrolytes (combine with solvents or plasticizers), these new SGPEs were prepared simply by curing different weight ratios of lithium bis(fluorosulfonyl)imide (LiFSI) with a methacrylic linear monomer, poly (ethylene glycol) dimethacrylate (PEGDMA). Noticeably, there were no solvents or plasticizers combined with the final SGPEs. Owing to this, the SGPEs showed high flexibility and strong mechanical stability. Some paramount physicochemical and electrochemical characters were observed. The SGPEs demonstrated good thermal stability below $150{ }^{\circ} \mathrm{C}$ and an extremely low glass transition temperature $\left(T_{g}\right)$ (around $-75^{\circ} \mathrm{C}$ ). Moreover, plastic crystal behaviors were also identified in this study. Ultimately, the SGPEs demonstrated excellent ionic conductivity at room temperature, which proves that these new SGPEs could be widely applied as a prospective electrolyte in flexible lithium-ion batteries.
\end{abstract}

Keywords: gel polymer electrolytes; UV curing; lithium bis(fluorosulfonyl)imide; room temperature ionic conductivity

\section{Introduction}

Lithium-ion batteries (LIBs) have been paid increasing attention in recent decades (since 1991) due to their high energy density, long cycle lives, and high efficiency. Meanwhile, they are widely applied in various mobile devices, electric vehicles, and energy storage areas [1-4]. Similarly to other types of battery, there are three indispensable components in an LIB: anode, cathode, and electrolyte. The electrolyte plays a critical role in transporting lithium ions between the pair of electrodes and determines the speed of energy release [5,6]. Organic liquid electrolytes have been commercialized for decades, and currently take up a large proportion of the batteries market owing to their excellent ambient temperature ionic conductivity. However, safety issues caused by leakage and flammability of organic liquid have become an obstacle to the development of LIBs; such safety issues cannot be ignored anymore and must be resolved as soon as possible [7-10]. Recently, solid polymer electrolytes (SPEs) have been introduced as alternative to traditional organic liquid electrolytes able to solve the aforementioned issues [11,12]. Extensive studies have shown that SPEs not only possess outstanding safety properties, but also suppress the growth of lithium dendrites. Moreover, SPEs can also be 
utilized as separators in LIBs because of their excellent mechanical stability [13-15]. Generally, SPEs are composed of polymer and lithium salts; lithium ions from the lithium salts can transfer through the free volume provided by the polymer [16]. To date, various materials have been reported and researched as polymer hosts, including poly (ethylene oxide) (PEO), poly (acrylonitrile) (PAN), poly (methyl methacrylate) (PMMA), and poly (vinylidene fluoride-hexafluoro propylene) (PVdF-HFP), etc. [17]. However, poor ambient temperature ionic conductivity $\left(10^{-5} \mathrm{~S} / \mathrm{cm}\right)$ of SPEs, which is caused by a high Ohmic drop in the electrolyte, is the main barrier limiting their wide application in LIBs [18-21]. To cope with this barrier, high-performance gelled polymer electrolytes (GPEs) have received great interest and have been investigated by some groups. Traditional GPEs are usually composed of SPEs and plasticizers or organic solvents which are utilized in liquid electrolytes; hence, GPEs can provide high ionic conductivity $\left(10^{-3} \mathrm{~S} / \mathrm{cm}\right)$ close to that of organic liquid electrolytes at room temperature and simultaneously maintain excellent mechanic stability similarly to SPEs $[14,17,22]$. However, it is also generally accepted that the mechanical stability of GPEs is sacrificed if the concentration of plasticizer or organic solvent is increased, even if the ionic conductivity is improved [23]. Meanwhile, GPEs combined with plasticizers and organic solvents in high concentrations can lead to bulky battery packages, and the leakage and flammability issues caused by organic solvents become a concern again [24]. Consequently, safe and high-performance electrolytes are still required.

To overcome the aforementioned issues, in this research, a series of high-ionic-conductivity self-standing gel polymer electrolytes (SGPEs) were fabricated by UV curing. UV curing is widely applied in the coatings industry for protecting the surface of various substrates. UV curing enables quick and simple polymerization and is quite environmentally friendly, besides which it allows formulation without any solvents. Furthermore, the glazed and smooth appearance which results from UV curing also could offer favorable interfacial contact with electrodes $[25,26]$. For the polymer matrix, a low-molecular-weight UV-curable poly (ethylene glycol) dimethacrylate (PEGDMA) was introduced as a new polymer matrix. PEO and its derivatives (PEGDMA) usually possess exceedingly high dielectric constants, resulting in high solubility of the lithium salts. The ethylene oxide units in PEGDMA offer a high donor number for alkali metals, so the Li ions can easily form a coordination linkage with them. With this coordination linkage (Li-O) forming and breaking, Li ions can jump along the PEGDMA chains to achieve ion transport. In addition, PEGDMA also has high chain flexibility owning to the low rotational energy barrier between oxygen and methylene, which is beneficial for the transport of Li ions. As a result, the high chain flexibility of PEGDMA is expected to improve the ionic conductivity $[27,28]$. For the lithium salt, LiFSI has been extensively studied as an electrolyte salt because of its high ionic conductivity comparable to $\mathrm{LiPF}_{6}$, and superior stability towards hydrolysis over $\mathrm{LiPF}_{6}$. Furthermore, $\mathrm{LiFSI}\left(0.45 \mathrm{ppm} \mathrm{Cl}^{-}\right)$demonstrates better stability with an $\mathrm{Al}$ current collector than LiTFSI [29]. These merits are can be attributed to the medium-range anion size of the FSI $^{-}$group, which exhibits promising chemical stability and dissociation [29-32]. LiFSI can also offer a significant impact in terms of decreasing the crystallinity of the electrolyte [33,34]. Finally, anhydrous acetone was added to obtain homogenous precursor electrolyte solutions; however, this was removed completely before the UV-curing process.

In order to compare the effect of the LiFSI on the SGPE properties, various weight ratios of SGPE were prepared. All the SGPEs were investigated by Fourier-transform infrared spectroscopy (FT-IR), thermal gravimetric analysis (TGA), differential scanning calorimetry (DSC), and X-ray diffraction (XRD), while the ionic conductivities were determined by electrochemical impedance spectroscopy (EIS). Finally, the ion transference number was measured to confirm the cations' mobility in the investigated electrolytes. 


\section{Experiment}

\subsection{Materials}

The chemical reagents, including polyethylene glycol dimethacrylate (PEGDMA, average Mn 550), photoinitiator 2-Hydroxy-2-methylpropiophenone (HMPP, 97\%), and lithium hexafluorophosphate solution in ethylene carbonate and dimethyl carbonate $(50 \mathrm{v} / 50 \mathrm{v})\left(1.0 \mathrm{M} \mathrm{LiPF}_{6}\right.$ in EC/DMC) were purchased from Aldrich (Seoul, South Korea). LiFSI was obtained from Chunbo Co., Ltd. (Chungju, South Korea). A Hg UV lamp (600 W) with an irradiation peak intensity of $200 \mathrm{~mW} / \mathrm{cm}^{2}$ was purchased from Lichtzen (Gunpo, South Korea). The acetone solvent was purified by distillation to remove water. The UV polymerization process and chemical structure are described in Figure 1.

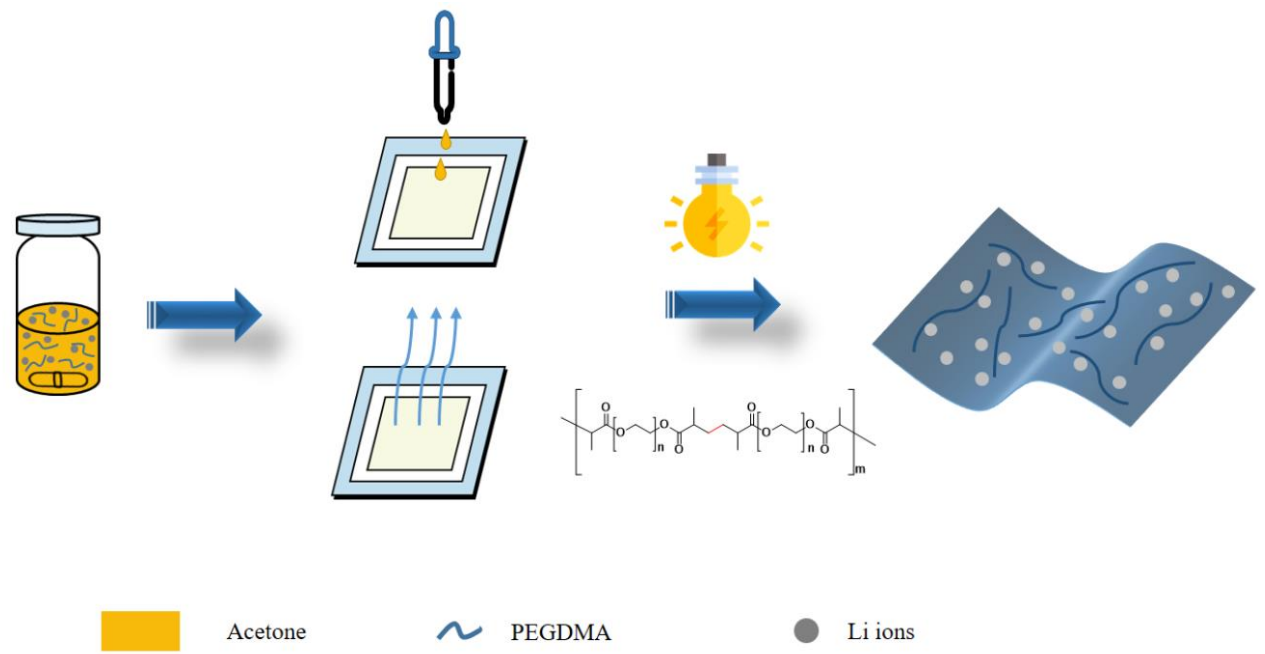

Figure 1. The process of fabricating a self-standing gel polymer electrolyte (SGPE) by UV curing. PEGDMA: poly (ethylene glycol) dimethacrylate.

\subsection{Fabrication of Self-Standing Gel Polymer Electrolytes}

The SGPE precursor solutions were prepared by dissolving different weight ratios of LiFSI into PEGDMA. Photoinitiator HMPP was then added into the solutions, wherein the concentration of HMPP was 1-2 wt.\% of the amount of PEGDMA. Anhydrous acetone was added finally to obtain a homogenous solution, wherein the ratio of acetone and mixture solution was 3:1 (v/w). Afterward, the mixture was stirred at room temperature for $\sim 3-4 \mathrm{~h}$ until all the starting materials had dissolved. The precursor solution was cast onto a glass plate $(8 \mathrm{~cm} \times 8 \mathrm{~cm})$ attached to a silicon mold $(6 \mathrm{~cm} \times 6 \mathrm{~cm}$, inside), and anhydrous acetone was removed in a vacuum oven at $40{ }^{\circ} \mathrm{C}$. Finally, the electrolyte modeling precursor was exposed to $\mathrm{Hg}$ UV lamp irradiation for $20 \mathrm{~min}$ to obtain a self-standing gel polymer electrolyte. All the SGPEs were fabricated through the same process. Herein, the "s" in SGPE sample names describes the wt.\% of LiFSI in the electrolytes.

\subsection{Characterization of Self-Standing Gel Polymer Electrolytes}

The polymerization of the SGPEs was confirmed by FT-IR (Nicolet iS5 FTIR Spectrometer, Waltham, MA, US) with a spectral resolution of $4 \mathrm{~cm}^{-1}$ at room temperature. Thermal stability behaviors were determined using a thermal gravimetric analyzer (Perkin-Elmer TGA-7, Massachusetts, US) from $25{ }^{\circ} \mathrm{C}$ to $500{ }^{\circ} \mathrm{C}$ at a heating rate of $10^{\circ} \mathrm{C} / \mathrm{min}$ under a nitrogen flow rate of $10 \mathrm{~mL} / \mathrm{min}$. The weight of the samples was controlled between 3 and $5 \mathrm{mg}$. Glass transition temperatures $\left(T_{g}\right)$ of the SGPEs were detected by DSC (Perkin-Elmer DSC 6000, Waltham, MA, US) from -80 to $120^{\circ} \mathrm{C}$ with a heating rate of $10^{\circ} \mathrm{C} / \mathrm{min}$ under a nitrogen gas atmosphere. XRD (Dmax2500/PC, Tokyo, Japan) was utilized to verify the plastic crystal behavior of the SGPEs and PEGDMA. The samples were scanned between 10 and $80^{\circ}$ with a speed rate of $2^{\circ} / \mathrm{min}$ at room temperature. In order to calculate the ionic 
conductivity $(\sigma, \mathrm{mS} / \mathrm{cm})$, EIS was done, primarily with an IM6ex, Zahner- Elektrik GmbH \& Co. KG instrument (Kronach, Germany) from 30 to $90{ }^{\circ} \mathrm{C}$ and over a frequency range of $0.1 \mathrm{~Hz}$ to $1 \mathrm{MHz}$ with an amplitude of $5 \mathrm{mV}$. All the EIS spectra were fitted with an appropriate equivalent circuit model using Z-view software (version 3.1, Scribner Associates Inc., US). To assemble a homemade cell (Figure 2), the SGPEs were sandwiched between two disks of conductive nickel foil and positioned between two FTO (Fluorine doped tin oxide) glass electrodes. The conductivity was calculated using Equation (1):

$$
\sigma=l /(R \times A)
$$

where $l$ and $A$ are the thickness and the area of the SGPEs, respectively. $R$ is the resistance value of the SGPEs.

Ion transference number $\left(t_{\mathrm{Li}+}\right)$ was measured with a symmetrical Swagelok cell Li/SGPEs/Li which was sealed inside an Ar-filled glove box, and was calculated in this work according to Equation (2):

$$
t_{\mathrm{Li}+}=I_{S}\left(\Delta V-I_{0} R_{0}\right) / I_{0}\left(\Delta V-I_{S} R_{S}\right)
$$

where $I_{0}, I_{S}, R_{0}, R_{S}$, and $\Delta V$ are the initial current, steady-state current, applied polarization voltage, initial resistances of passivation layers, and the steady-state resistances of passivation layers, respectively.

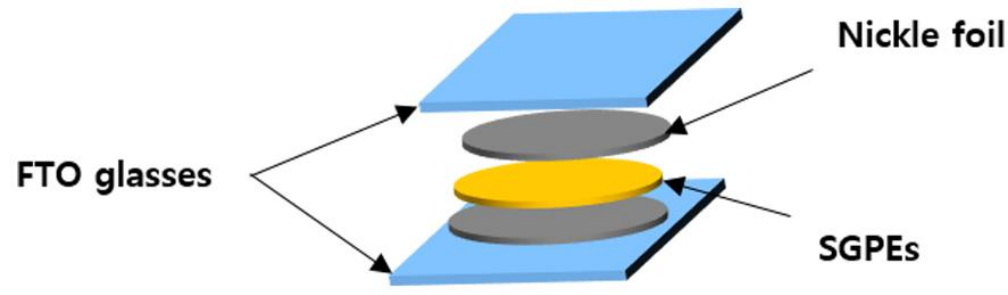

Figure 2. Illustration of the homemade cell assembly.

\section{Results and Discussion}

A series of SGPEs were fabricated with the precursor mixture solutions through UV-curing polymerizations, and the appearances of SGPEs are presented in Figure 3. The precursor solutions turned to transparent and flexible electrolyte films which could readily be peeled away from glass plates. The thickness of the SGPEs was controlled under $300 \mu \mathrm{m}$ by adjusting the silicon mold size and the amount of precursor solutions. SGPE50 is not presented here as its excessive lithium salt content led to the inability to fabricate an intact electrolyte film. The chemical structure and UV polymerization of the SGPEs were confirmed by FT-IR. Before UV curing, the PEGDMA characteristic absorption peaks of the $C=C$ and $C=O$ double bonds were present at $1640 \mathrm{~cm}^{-1}$ and $1725 \mathrm{~cm}^{-1}$, respectively, as shown in Figure 4. After UV curing, only the $\mathrm{C}=\mathrm{O}$ double bonds remained at $1725 \mathrm{~cm}^{-1}$, while the peak of the $\mathrm{C}=\mathrm{C}$ double bond disappeared. Furthermore, $\mathrm{S}=\mathrm{O}$ stretch peaks typical of LiFSI were located at $1376 \mathrm{~cm}^{-1}$ and $1172 \mathrm{~cm}^{-1}$ whether before UV curing or after. The FT-IR graph suggests that polymerization of SGPEs was achieved after UV curing and that LiFSI was still present after the curing process.

Heat is produced when batteries operate, and overheating is one of the most common causes of LIB accidents. As a result, all of the components in batteries require favorable thermal stabilities, including electrolytes and separators [35,36]. Thermal characteristics were detected by TGA and DSC, respectively. It is shown in Figure 5 that pure PEGDMA possessed the best thermal stability, with weight degradation beginning from $175^{\circ} \mathrm{C}$. In contrast, the commercial liquid electrolyte $(1.0 \mathrm{M}$ $\mathrm{LiPF}_{6}$ in $\mathrm{EC} / \mathrm{DMC}$ ) displayed the lowest heat endurance, and its weight declined sharply from the beginning. In the case of the SGPEs, weight loss began slightly at $150{ }^{\circ} \mathrm{C}$ and dramatically increased from $210^{\circ} \mathrm{C}$, which corresponded with the thermal stability of LiFSI and PEGDMA. Figure 5 indicates 
that compared with commercial liquid electrolyte, the SGPEs possess more promising thermal stability, which could improve the battery thermal stability and safety.
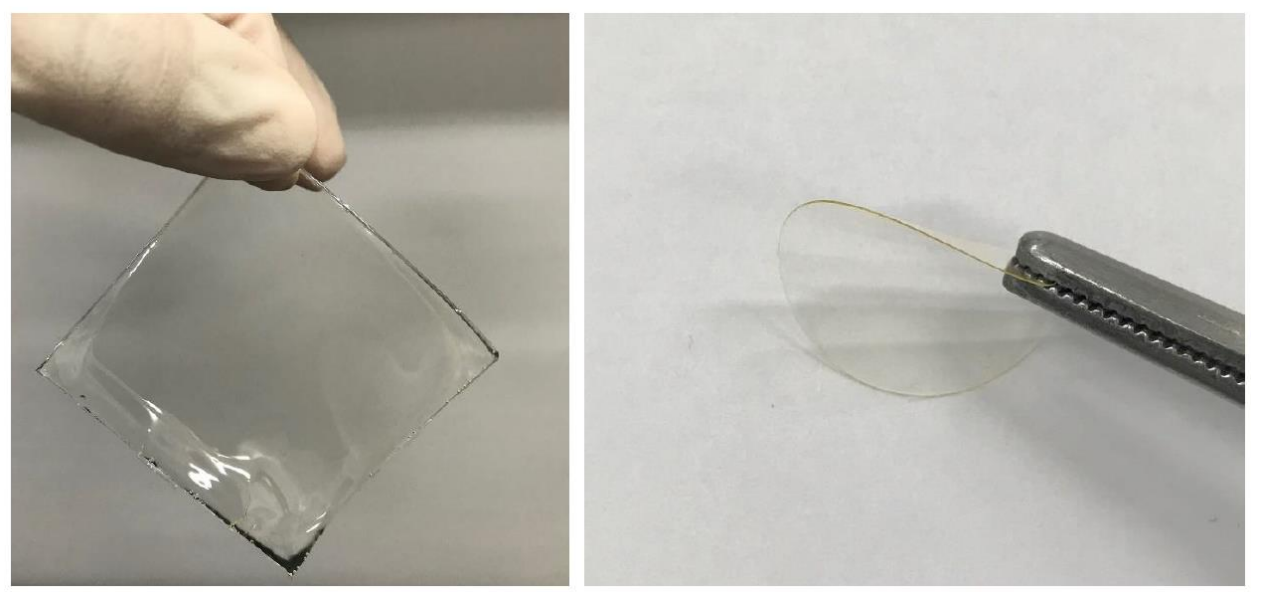

Figure 3. The physical appearance of the SGPEs at room temperature.

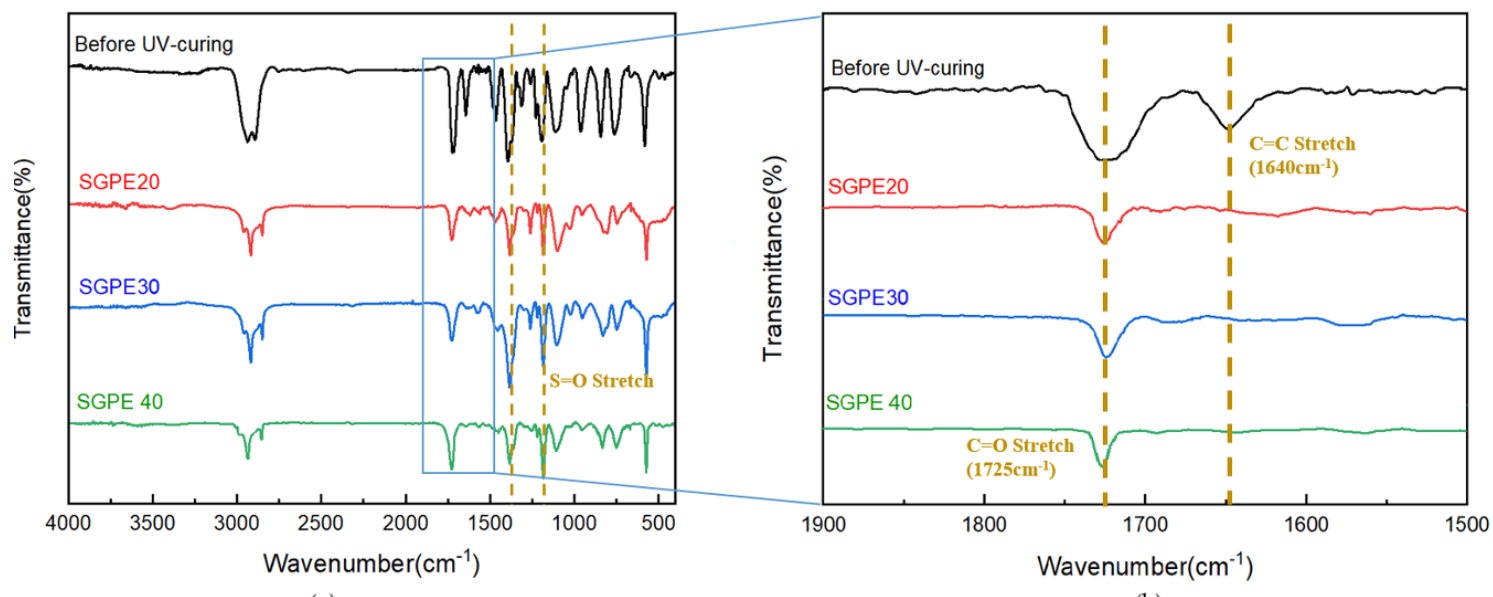

(a)

(b)

Figure 4. FT-IR spectra of (a) SGPEs before/ after UV curing and (b) acrylic $\mathrm{C}=\mathrm{C}$ bonds in the SGPEs before/ after UV curing.

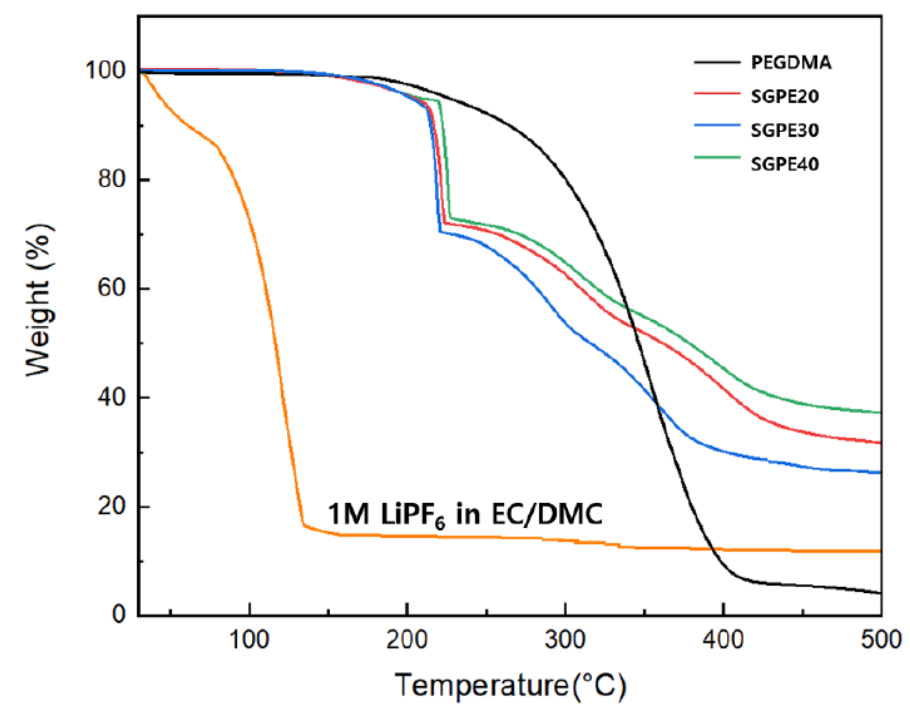

Figure 5. Thermal stability of pure PEGDMA, SGPEs, and 1M LiPF6 in ethylene carbonate and dimethyl carbonate (EC/DMC). 
According to Vogel-Tammann-Fulcher behavior, the $T_{g}$ of a polymer is related to its free volume and ionic conductivity. Generally, ionic conductivity shows a reciprocal relationship with $T_{g}$; decreasing the $T_{g}$ of the material increases the ionic conductivity of the electrolyte [37,38]. In Figure 6, the SGPEs presented extremely low $T_{g}$ : $-75.33{ }^{\circ} \mathrm{C}$ (SGPE20), $-74.47{ }^{\circ} \mathrm{C}$ (SGPE30), and $-74.02{ }^{\circ} \mathrm{C}$ (SGPE40)—significantly lower than pure PEGDMA $\left(-69.54^{\circ} \mathrm{C}\right)$. A small increase was seen with the decline of PEGDMA concentration, but $T_{g}$ remained at around $-74{ }^{\circ} \mathrm{C}$. In addition, there was no endothermic peak observed with increased temperature, indicating that the SGPEs have no melting point. The DSC graph demonstrates that after UV curing, amorphous SGPEs with excellent $T_{g}$ were obtained. Due to the different concentrations of LiFSI in the SGPEs, slight fluctuations of $T_{g}$ were observed, but the plastic crystal behaviors of the SGPEs were not disrupted.

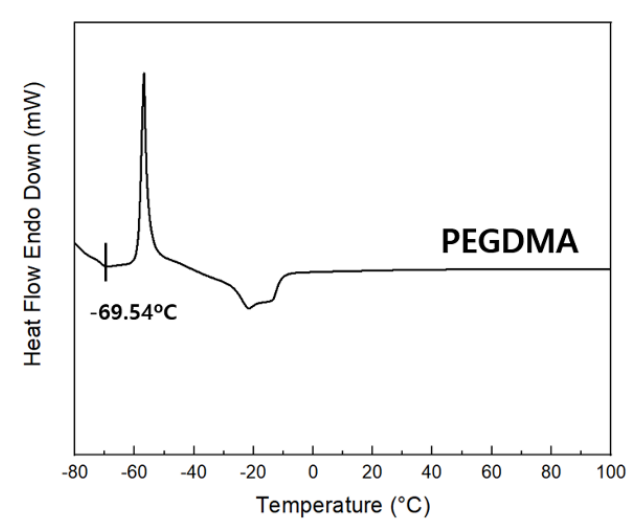

(a)

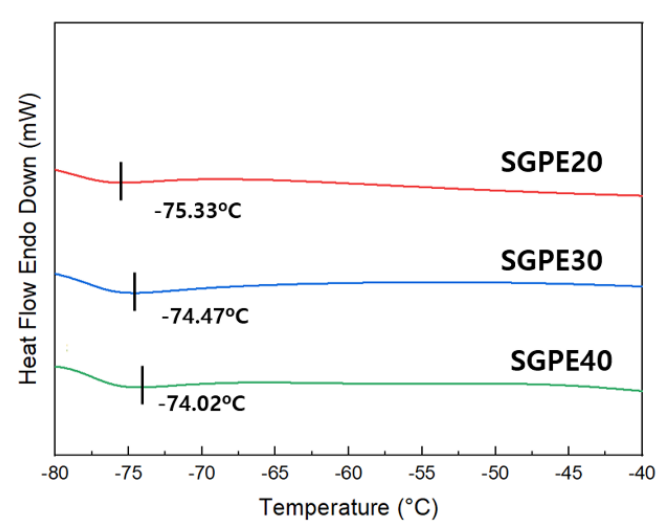

(b)

Figure 6. Glass transition temperatures of (a) PEGDMA and (b) SGPEs.

As mentioned above, the crystal phase is considered as the main factor that retards polymer chain dynamics and leads to low ion transportation. This phenomenon can be relieved by the use of an amorphous phase with activated chain segments [27]. The plastic crystal behaviors of PEGDMA and SGPEs were confirmed by XRD analysis. As shown in Figure 7, it was apparent that pure PEGDMA monomer displayed a big broad peak at $20^{\circ}$, which corresponded to the crystalline property of PEGDMA. In contrast to this, after UV curing, this typical peak was dramatically declined to a tiny one for the SGPEs, confirming that amorphous SGPEs had been obtained. Moreover, the SGPEs also demonstrated a reduced crystal phase compared to the pure PEGMDA film, suggesting that LiFSI suppressed the crystal phase considerably.

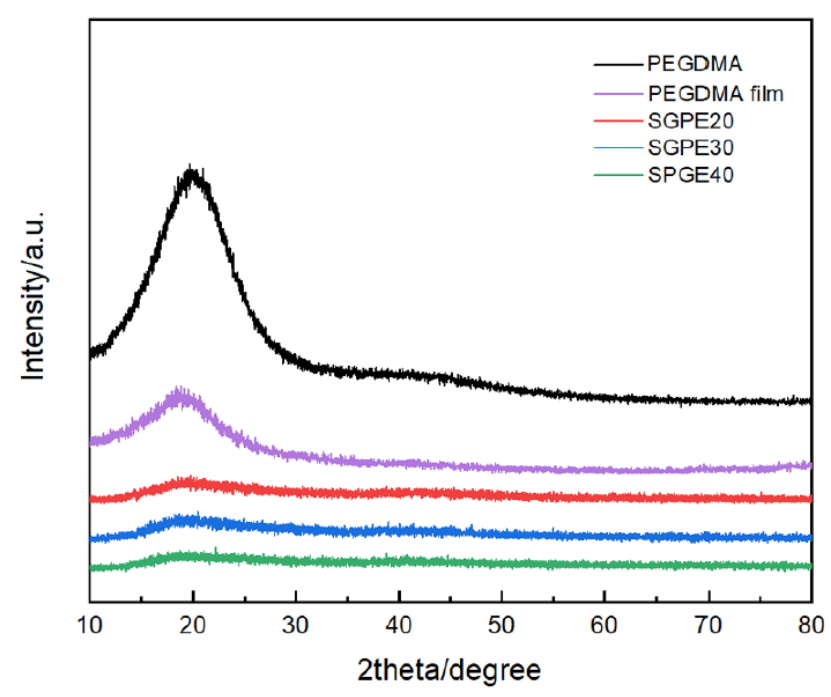

Figure 7. X-ray diffraction (XRD) pattern of pure PEGDMA, PEGDMA film, and SGPEs. 
The ionic conductivity of electrolytes is one of the most critical factors for LIBs, indicating the movement ability of lithium ions in an electrolyte. It is also the main barrier to commercialization of polymer electrolytes in LIBs. In order to study the ionic conductivity of the SGPEs, EIS is carried out at different temperatures from 30 to $90^{\circ} \mathrm{C}$, and the Nyquist plots are displayed in Figure 8. Note that only SGPE30 and SGPE40 are discussed in this section, since the impedance of SGPE20 was too high to be used as a reference. It is obvious that SGPE40 had lower resistance compared to SGPE30; this trend applied to the whole measured temperature range. According to Equation (1), these results can directly affect the ionic conductivities of SGPEs. As shown in Figure 9 and Table 1, both SGPE30 $(\sigma=1.11 \mathrm{mS} / \mathrm{cm})$ and SGPE40 $(\sigma=5.21 \mathrm{mS} / \mathrm{cm})$ reached a favorable level of ionic conductivity at room temperature, extremely close to that of the the liquid electrolyte. Additionally, SGPE40 was observed to have higher ionic conductivity than that of SGPE30 throughout the investigated temperature range. In other words, at a given temperature, SGPE40 had superior Li-ionic conduction to SGPE30. This may imply that in a network system, ionic conductivity can be improved by increasing the amount of LiFSI. All the SGPE ionic conductivities climbed moderately with the growth of temperature. The lithium-ion transference number of unit indicated that the ion transport and rate performance of the battery were dominated exclusively by lithium ions [24]. Many attempts have been made to improve the transference number of polymer electrolytes to meet the requirements of LIBs. According to the report, crystalline PEO-based electrolytes usually offer quite low transference numbers $(<0.20)$, even at Li salt concentrations greater than 30 mol.\% [39]. Figure 10a, b shows the chronoamperometry curves of the symmetrical Swagelok Li/SGPEs/Li cells at a polarization voltage of $10 \mathrm{mV}$, and the inset of Figure 10 shows the Nyquist plots of the dummy cell before and after polarization. Figure 10c displays the values of $t_{\mathrm{Li}+}$ dependent on LiFSI concentration for SGPEs; the values of $t_{\mathrm{Li}+}$ increased with increasing concentration of LiFSI up to 0.40 at a concentration of $40 \mathrm{wt}$ \%, which is higher than general PEO-based electrolytes. However, SGPE30 only reached 0.15 due to its low concentration of LiFSI.

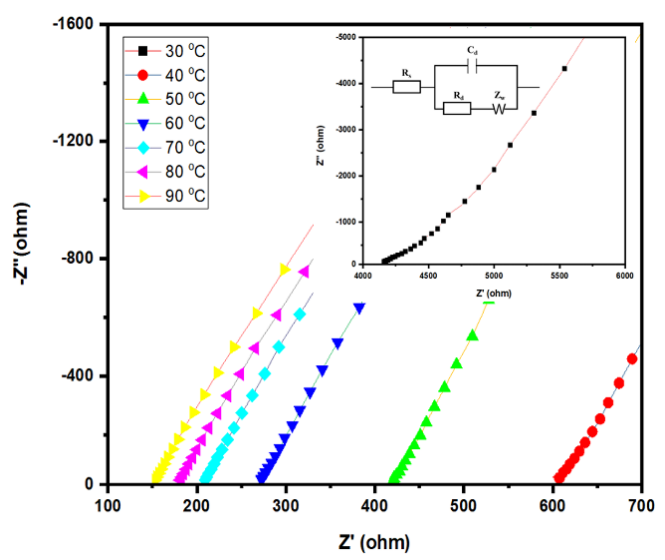

(a)

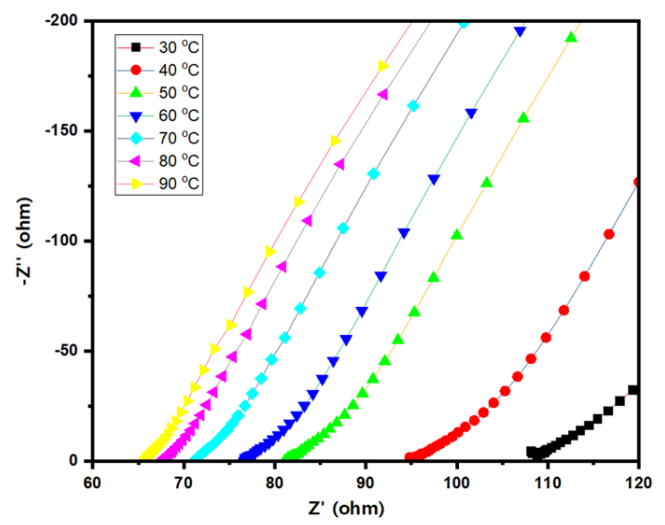

(b)

Figure 8. Nyquist plots of (a) SGPE30 and (b) SGPE40. 


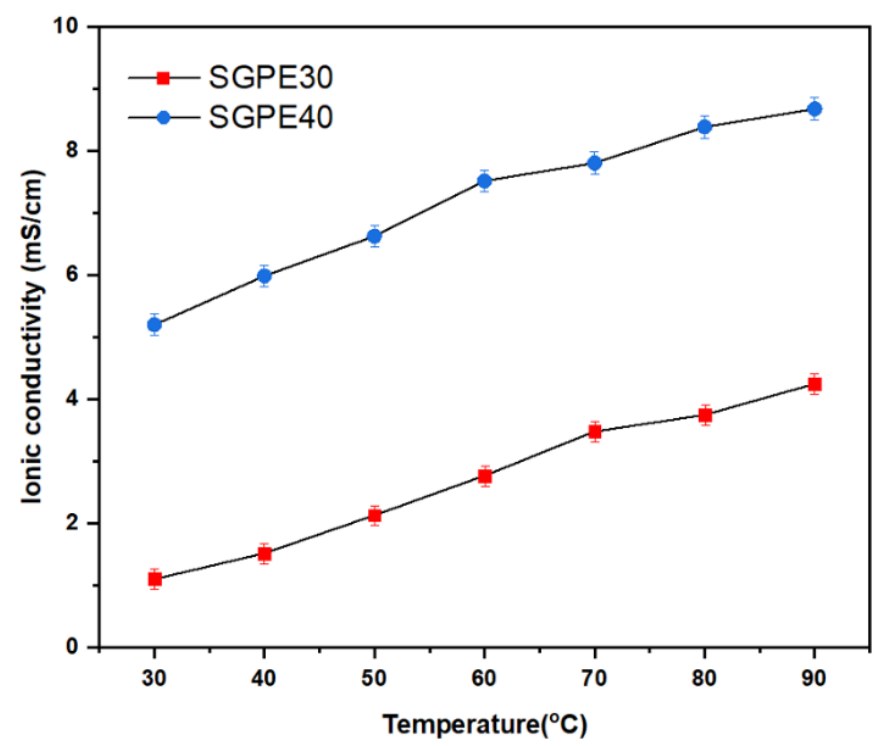

Figure 9. Temperature-dependent ionic conductivity of SGPE30 and SGPE40.

Table 1. Ionic conductivity of solvent-free electrolyte at different temperatures.

\begin{tabular}{cccccccc}
\hline Sample & $\mathbf{3 0}{ }^{\circ} \mathbf{C}$ & $\mathbf{4 0}{ }^{\circ} \mathbf{C}$ & $\mathbf{5 0}{ }^{\circ} \mathbf{C}$ & $\mathbf{6 0}{ }^{\circ} \mathbf{C}$ & $\mathbf{7 0}{ }^{\circ} \mathbf{C}$ & $\mathbf{8 0}{ }^{\circ} \mathbf{C}$ & $\mathbf{9 0}{ }^{\circ} \mathbf{C}$ \\
\hline SGPE30 & $1.11^{1}$ & 1.52 & 2.13 & 2.77 & 3.48 & 3.75 & 4.25 \\
SGPE40 & 5.21 & 5.99 & 6.63 & 7.52 & 7.81 & 8.39 & 8.38 \\
\hline \multicolumn{7}{c}{$1 \mathrm{mS} / \mathrm{cm}}$.
\end{tabular}
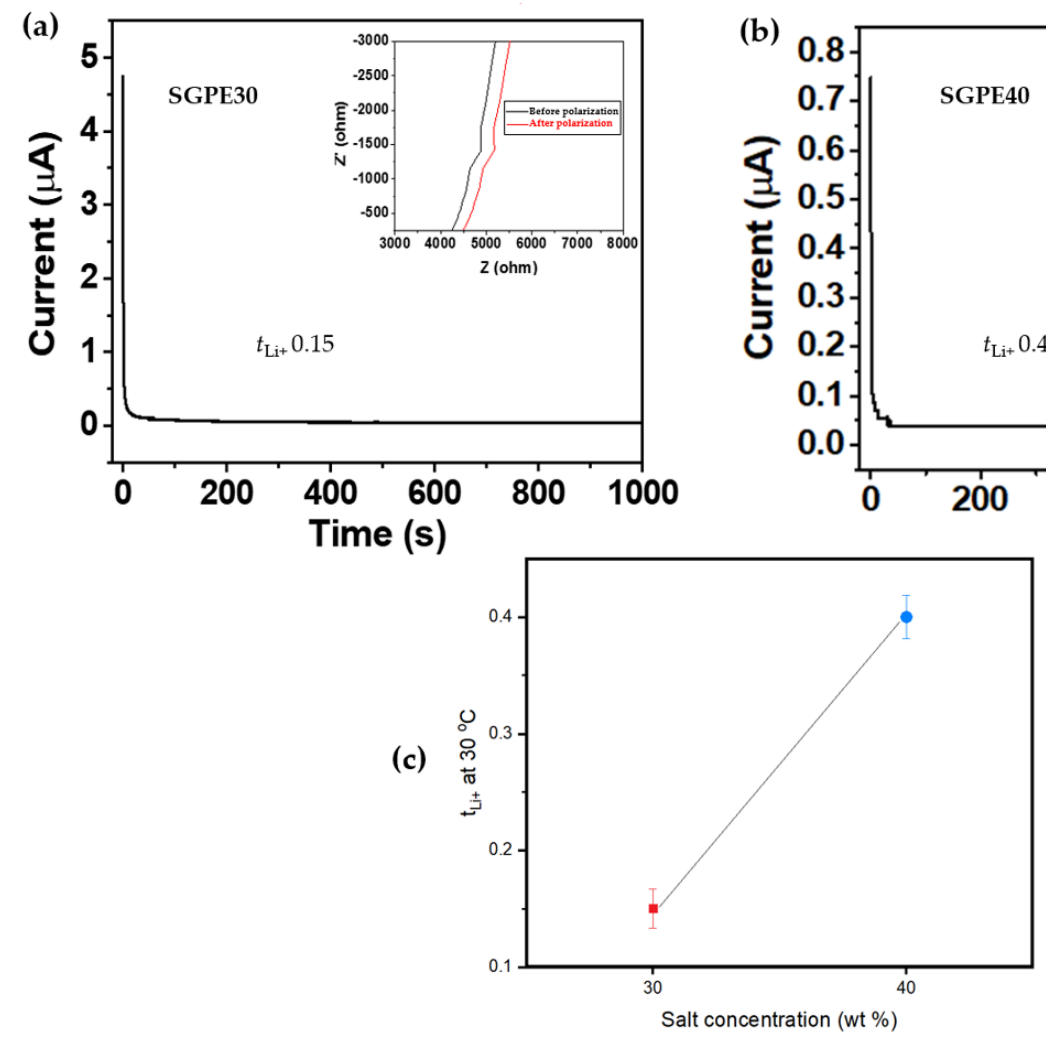

(b)

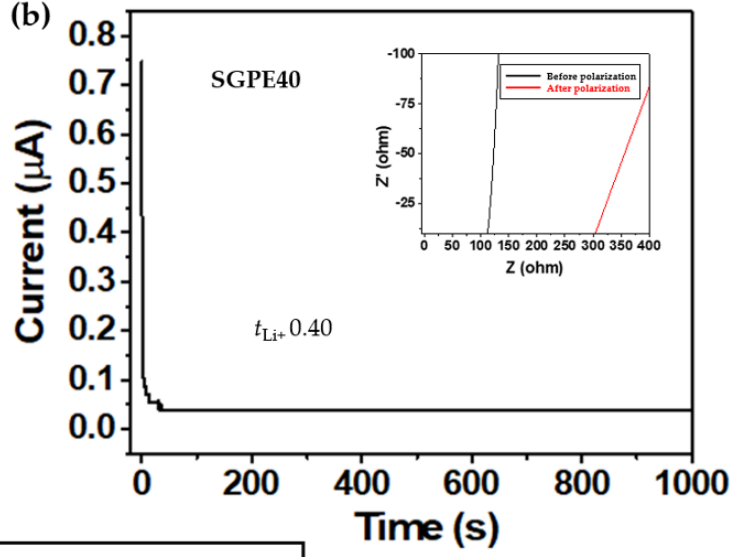

Figure 10. $t_{\mathrm{Li}+}$ values for (a) SGPE30, (b) SGPE40, and (c) dependence of $t_{\mathrm{Li}+}$ on salt concentration for SGPEs at $30{ }^{\circ} \mathrm{C}$. 


\section{Conclusion}

In this work, different weight ratios of LiFSI was used as the lithium salt in fabrication of a highly conductive and flexible polymer electrolyte for LIBs. The electrolyte polymerization was carried out by UV curing at room temperature, and it was observed that a high lithium salt concentration $(\geq 50 \%)$ made it difficult to form an intact electrolyte film by this method. Thus, SGPE20, SGPE30, and SGPE40 were investigated in detail. The SGPEs displayed satisfactory thermal stability below $150{ }^{\circ} \mathrm{C}$ and extremely low $T_{g}$ (around $-75^{\circ} \mathrm{C}$ ), demonstrating that the concentration of LiFSI had a very slight effect on the thermal properties of SGPEs. Additionally, all the SGPEs displayed similar plastic crystal behaviors (amorphous) after the UV-curing reaction. Excellent ionic conductivity of both SGPE30 $(1.11 \mathrm{mS} / \mathrm{cm})$ and SGPE40 $(5.21 \mathrm{mS} / \mathrm{cm})$ were observed at room temperature; the impedance of SGPE20 was so high that it could not be measured here. Moreover, different lithium-ion transference numbers were confirmed for SGPE30 (0.15) and SGPE40 (0.40), implying that ionic conductivity and transference numbers were effectively increased by enhancing the concentration of LiFSI. Summarized above, this work demonstrated the breakthrough that a self-standing gel polymer electrolyte based on PEGDMA and LiFSI can be a candidate electrolyte polymer for LIB applications. Comprehensive battery tests will need to be conducted for this type of electrolyte in order to move towards commercialization.

Author Contributions: Conceptualization, W.K. and H.J.; methodology, L.J.; software, Y.L. and D.K.; validation, L.J., F.A. and H.J.; formal analysis, T.R.; investigation, L.J., S.Y. and W.Z.; resources, W.K.; data curation, F.A.; writing-original draft preparation, L.J.; writing—review and editing, W.K.; visualization, L.J.; supervision, H.J.; project administration, W.K.

Funding: This research received no external funding.

Acknowledgments: This work was supported by Konkuk University 2019.

Conflicts of Interest: The authors declare no conflict of interest.

\section{References}

1. Hannan, M.A.; Lipu, M.S.H.; Hussain, A.; Mohamed, A. A Review of Lithium-Ion Battery State of Charge Estimation and Management System in Electric Vehicle Applications: Challenges and Recommendations. Renew. Sustain. Energy Rev. 2017, 78, 834-854. [CrossRef]

2. Lu, L.; Han, X.; Li, J.; Hua, J.; Ouyang, M. A Review on the Key Issues for Lithium-Ion Battery Management in Electric Vehicles. J. Power Sources 2013, 226, 272-288. [CrossRef]

3. Saw, L.H.; Ye, Y.; Tay, A.A.O. Integration Issues of Lithium-Ion Battery into Electric Vehicles Battery Pack. J. Clean. Prod. 2016, 113, 1032-1045. [CrossRef]

4. Blomgren, G.E. The Development and Future of Lithium Ion Batteries. J. Electrochem. Soc. 2017, 164, A5019-A5025. [CrossRef]

5. $\mathrm{Xu}, \mathrm{K}$. Nonaqueous Liquid Electrolytes for Lithium-Based Rechargeable Batteries Nonaqueous Liquid Electrolytes for Lithium-Based Rechargeable Batteries. Chem. Rev. 2004, 104, 4303-4417. [CrossRef] [PubMed]

6. Tarascon, J.-M.; Armand, M. Issues and Challenges Facing Rechargeable Lithium Batteries. Nature 2001, 414, 359-367. [CrossRef]

7. Watanabe, M.; Thomas, M.L.; Zhang, S.; Ueno, K.; Yasuda, T.; Dokko, K. Application of Ionic Liquids to Energy Storage and Conversion Materials and Devices. Chem. Rev. 2017, 117, 7190-7239. [CrossRef]

8. Zhou, D.; Liu, R.; Zhang, J.; Qi, X.; He, Y.-B.; Li, B.; Yang, Q.-H.; Hu, Y.-S.; Kang, F. In Situ Synthesis of Hierarchical Poly(Ionic Liquid)-Based Solid Electrolytes for High-Safety Lithium-Ion and Sodium-Ion Batteries. Nano Energy 2017, 33, 45-54. [CrossRef]

9. Rollins, H.W.; Harrup, M.K.; Dufek, E.J.; Jamison, D.K.; Sazhin, S.V.; Gering, K.L.; Daubaras, D.L. Fluorinated Phosphazene Co-Solvents for Improved Thermal and Safety Performance in Lithium-Ion Battery Electrolytes. J. Power Sources 2014, 263, 66-74. [CrossRef]

10. Tsao, C.-H.; Su, H.-M.; Huang, H.-T.; Kuo, P.-L.; Teng, H. Immobilized Cation Functional Gel Polymer Electrolytes with High Lithium Transference Number for Lithium Ion Batteries. J. Memb. Sci. 2019, 572, 382-389. [CrossRef] 
11. Manthiram, A.; Yu, X.; Wang, S. Lithium Battery Chemistries Enabled by Solid-State Electrolytes. Nat. Rev. Mater. 2017, 2, 16103:1-16103:16. [CrossRef]

12. Fu, K.K.; Gong, Y.; Dai, J.; Gong, A.; Han, X.; Yao, Y.; Wang, C.; Wang, Y.; Chen, Y.; Yan, C.; et al. Flexible, Solid-State, Ion-Conducting Membrane with 3D Garnet Nanofiber Networks for Lithium Batteries. Proc. Natl. Acad. Sci. USA 2016, 113, 7094-7099. [CrossRef] [PubMed]

13. Khurana, R.; Schaefer, J.L.; Archer, L.A.; Coates, G.W. Suppression of Lithium Dendrite Growth Using Cross-Linked Polyethylene/Poly (Ethylene Oxide) Electrolytes: A New Approach for Practical Lithium-Metal Polymer Batteries. J. Am. Chem. Soc. 2014, 136, 7395-7402. [CrossRef] [PubMed]

14. Liu, R.; Wu, Z.; He, P.; Fan, H.; Huang, Z.; Zhang, L.; Chang, X.; Liu, H.; Wang, C.; Li, Y. A Self-Standing, UV-Cured Semi-Interpenetrating Polymer Network Reinforced Composite Gel Electrolytes for Dendrite-Suppressing Lithium Ion Batteries. J. Mater. 2018, 5. [CrossRef]

15. Wang, C.; Yang, Y.; Liu, X.; Zhong, H.; Xu, H.; Xu, Z.; Shao, H.; Ding, F. Suppression of Lithium Dendrite Formation by Using LAGP-PEO (LiTFSI) Composite Solid Electrolyte and Lithium Metal Anode Modified by PEO (LiTFSI) in All-Solid-State Lithium Batteries. ACS Appl. Mater. Interfaces 2017, 9, 13694-13702. [CrossRef] [PubMed]

16. Cui, Y.; Liang, X.; Chai, J.; Cui, Z.; Wang, Q.; He, W.; Liu, X.; Liu, Z.; Cui, G.; Feng, J. High Performance Solid Polymer Electrolytes for Rechargeable Batteries: A Self-Catalyzed Strategy toward Facile Synthesis. Adv. Sci. 2017, 4, 1700174. [CrossRef] [PubMed]

17. Manuel Stephan, A. Review on Gel Polymer Electrolytes for Lithium Batteries. Eur. Polym. J. 2006, 42, 21-42. [CrossRef]

18. Christopher Bachman, J.; Muy, S.; Grimaud, A.; Chang, H.-H.; Pour, N.; Lux, S.F.; Paschos, O.; Maglia, F.; Lupart, S.; Lamp, P.; et al. Inorganic Solid-State Electrolytes for Lithium Batteries: Mechanisms and Properties Governing Ion Conduction. Chem. Rev. 2016, 116, 140-162. [CrossRef]

19. Kobayashi, Y.; Mita, Y.; Seki, S.; Ohno, Y.; Miyashiro, H. Comparative Study of Lithium Secondary Batteries Using Nonvolatile Safety Electrolytes. J. Electrochem. Soc. 2007, 154, A677-A681. [CrossRef]

20. Palacin, M.R. Recent Advances in Rechargeable Battery Materials: A Chemist's Perspective. Chem. Soc. Rev. 2009, 38, 2565-2575. [CrossRef]

21. Yue, L.; Ma, J.; Zhang, J.; Zhao, J.; Dong, S.; Liu, Z.; Cui, G.; Chen, L. All Solid-State Polymer Electrolytes for High-Performance Lithium Ion Batteries. Energy Storage Mater. 2016, 5, 139-164. [CrossRef]

22. Song, J.Y.; Wang, Y.Y.; Wan, C.C. Review of Gel-Type Polymer Electrolytes for Lithium-Ion Batteries. J. Power Sources 1999, 77, 183-197. [CrossRef]

23. Qian, X.; Gu, N.; Cheng, Z.; Yang, X.; Wang, E.; Dong, S. Plasticizer Effect on the Ionic Conductivity of PEO-Based Polymer Electrolyte. Mater. Chem. Phys. 2002, 74, 98-103. [CrossRef]

24. He, R.; Echeverri, M.; Ward, D.; Zhu, Y.; Kyu, T. Highly Conductive Solvent-Free Polymer Electrolyte Membrane for Lithium-Ion Batteries: Effect of Prepolymer Molecular Weight. J. Memb. Sci. 2016, 498, $208-217$. [CrossRef]

25. Decker, C. Kinetic Study and New Applications of UV Radiation Curing. Macromol. Rapid Commun. 2002, 23, 1067-1093. [CrossRef]

26. Allen, N.S. Photoinitiators for UV and Visible Curing of Coatings: Mechanisms and Properties. J. Photochem. Photobiol. A Chem. 1996, 100, 101-107. [CrossRef]

27. Xue, Z.; He, D.; Xie, X. Poly(Ethylene Oxide)-Based Electrolytes for Lithium-Ion Batteries. J. Mater. Chem. A 2015, 3, 19218-19253. [CrossRef]

28. Devaux, D.; Bouchet, R.; Glé, D.; Denoyel, R. Mechanism of Ion Transport in PEO/LiTFSI Complexes: Effect of Temperature, Molecular Weight and End Groups. Solid State Ionics 2012, 227, 119-127. [CrossRef]

29. Han, H.-B.; Zhou, S.-S.; Zhang, D.-J.; Feng, S.-W.; Li, L.-F.; Liu, K.; Feng, W.-F.; Nie, J.; Li, H.; Huang, X.-J.; et al. Lithium Bis (Fluorosulfonyl) Imide (LiFSI) as Conducting Salt for Nonaqueous Liquid Electrolytes for Lithium-Ion Batteries: Physicochemical and Electrochemical Properties. J. Power Sources 2011, 196, 3623-3632. [CrossRef]

30. Hu, J.J.; Long, G.K.; Liu, S.; Li, G.R.; Gao, X.P. A LiFSI-LiTFSI Binary-Salt Electrolyte to Achieve High Capacity and Cycle Stability for a Li-S Battery. Chem. Commun. 2014, 50, 14647-14650. [CrossRef]

31. Kang, S.-J.; Park, K.; Park, S.-H.; Lee, H. Unraveling the Role of LiFSI Electrolyte in the Superior Performance of Graphite Anodes for Li-Ion Batteries. Electrochim. Acta 2018, 259, 949-954. [CrossRef] 
32. Philippe, B.; Dedryvère, R.; Gorgoi, M.; Rensmo, H.; Gonbeau, D.; Edström, K. Improved Performances of Nanosilicon Electrodes Using the Salt LiFSI: A Photoelectron Spectroscopy Study. J. Am. Chem. Soc. 2013, 135, 9829-9842. [CrossRef]

33. Zhang, H.; Liu, C.; Zheng, L.; Xu, F.; Feng, W.; Li, H.; Huang, X.; Armand, M.; Nie, J.; Zhou, Z. Lithium Bis (Fluorosulfonyl) Imide/Poly (Ethylene Oxide) Polymer Electrolyte. Electrochim. Acta 2014, 133, 529-538. [CrossRef]

34. Judez, X.; Zhang, H.; Li, C.; González-Marcos, J.A.; Zhou, Z.; Armand, M.; Rodriguez-Martinez, L.M. Lithium Bis (Fluorosulfonyl) Imide/Poly (Ethylene Oxide) Polymer Electrolyte for All Solid-State Li-S Cell. J. Phys. Chem. Lett. 2017, 8, 1956-1960. [CrossRef] [PubMed]

35. Khateeb, S.A.; Amiruddin, S.; Farid, M.; Selman, J.R.; Al-Hallaj, S. Thermal Management of Li-Ion Battery with Phase Change Material for Electric Scooters: Experimental Validation. J. Power Sources 2005, 142, 345-353. [CrossRef]

36. Arbizzani, C.; Gabrielli, G.; Mastragostino, M. Thermal Stability and Flammability of Electrolytes for Lithium-Ion Batteries. J. Power Sources 2011, 196, 4801-4805. [CrossRef]

37. He, R.; Kyu, T. Effect of Plasticization on Ionic Conductivity Enhancement in Relation to Glass Transition Temperature of Crosslinked Polymer Electrolyte Membranes. Macromolecules 2016, 49, 5637-5648. [CrossRef]

38. Hu, P.; Chai, J.; Duan, Y.; Liu, Z.; Cui, G.; Chen, L. Progress in Nitrile-Based Polymer Electrolytes for High Performance Lithium Batteries. J. Mater. Chem. A 2016, 4, 10070-10083. [CrossRef]

39. Tominaga, Y. Ion-conductive polymer electrolytes based on poly (ethylene carbonate) and its derivatives. Polym. J. 2017, 49, 291-299. [CrossRef]

(C) 2019 by the authors. Licensee MDPI, Basel, Switzerland. This article is an open access article distributed under the terms and conditions of the Creative Commons Attribution (CC BY) license (http://creativecommons.org/licenses/by/4.0/). 